Abstracta Iranica Iranica

Revue bibliographique pour le domaine irano-aryen

Volume 32-33 | 2013

Comptes rendus des publications de 2009-2010

\title{
Sonja Brentjes. The Mathematical Sciences in Safavid Iran: Questions and Perspectives
}

\section{Živa Vesel}

\section{(2) OpenEdition \\ 12 Journals}

\section{Édition électronique}

URL : http://journals.openedition.org/abstractairanica/40704

DOI : 10.4000/abstractairanica.40704

ISSN : 1961-960X

Éditeur :

CNRS (UMR 7528 Mondes iraniens et indiens), Éditions de l'IFRI

\section{Édition imprimée}

Date de publication : 1 décembre 2013

ISSN : 0240-8910

\section{Référence électronique}

Živa Vesel, «Sonja Brentjes. The Mathematical Sciences in Safavid Iran: Questions and Perspectives », Abstracta Iranica [En ligne], Volume 32-33 | 2013, document 395, mis en ligne le 01 juillet 2016,

consulté le 27 septembre 2020. URL : http://journals.openedition.org/abstractairanica/40704 ; DOI : https://doi.org/10.4000/abstractairanica.40704

Ce document a été généré automatiquement le 27 septembre 2020.

Tous droits réservés 


\title{
Sonja Brentjes. The Mathematical Sciences in Safavid Iran: Questions and Perspectives
}

\author{
Živa Vesel
}

\section{RÉFÉRENCE}

Sonja Brentjes. « The Mathematical Sciences in Safavid Iran: Questions and

Perspectives ", in : D. Hermann \& F. Speziale, eds., Muslim Cultures in the Indo-Iranian World during the Early-Modern and Modern Periods. Berlin, Klaus Schwarz Verlag, 2010, p. 325-402.

1 L'A. fait une mise au point sur la situation des activités mathématiques sous les Safavides, sujet peu exploré sauf exception (par ex., l'œuvre de Šams al-dīn Hafrī étudié par G. Saliba, d'une part ; les mappemondes, figurant sur des astrolabes, centrées sur la Mecque, étudiées par D. A. King, de l'autre) et plaide pour une approche historique et culturelle laquelle ne se limiterait pas à la recherche exclusive de l'innovation et du progrès dans le domaine. L'A. démontre qu'il existe, dans l'Iran safavide, un riche répertoire d'activités mathématiques, sous des formes diverses, au niveau du mécénat de cour et de l'enseignement (dont celui de la madrasa), qui se traduisent en particulier par la productions de textes - abondamment cités dans l'article (des commentaires, des copies de textes antérieurs, parfois illustrés ou ornementés, etc.). L'A. établit un parallèle entre l'Iran safavide, ses contemporains (les Empires ottoman et moghol) et ses prédécesseurs (notamment les Timurides) et pose des questions pertinentes, notamment à propos du contexte, qui sont à même de motiver de nouvelles études (telle l'importance des réseaux savants d'une ville face aux milieux de la cour). 


\section{AUTEURS}

ŽIVA VESEL

CNRS, Mondes iranien et indien, Paris 